\title{
Brief Analysis of Engineering Geological Monitoring
}

\section{Fangfang Wang}

No.6 Institute of Geology and Mineral Resources Exploration of Shandong Province, Weihai, Shandong, 264209, China

\begin{abstract}
The dynamic observation of various geological processes must be carried out on the basis of clarifying the geological conditions, so that the development conditions and the main factors affecting development can be identified based on the observation data, and the similar geological processes in areas with similar engineering geological conditions can be predicted based on the observation data dynamic.
\end{abstract}

\section{Keywords}

geological monitoring; rock and soil; groundwater

\section{工程地质监测简析}

\author{
王方方 \\ 山东省第六地质矿产勘查院，中国・山东 威海 264209
}

\section{摘 要}

各种地质作用的动态观测必须在查清地质条件的基础上进行, 这样才能根据观测资料判明其发育条件和影响发育的主要因素, 也才能根据观测资料预测工程地质条件类似区的同类地质作用的动态。

\section{关键词}

地质监测; 岩土体; 地下水

\section{1 岩土体性质与状态的监测}

岩土体性质和状态的现场监测, 可以归纳为岩土体变形 观测和岩土体内部应力的观测两大方面。如果工程需要进行 岩土体的监测, 则岩土体的监测内容应包括以下 3 个方面: (1)洞室或岩石边坡的收玫量测; (2)深基坑开挖的回弹量测: (3)土压力或岩体应力量测。

岩土体性状监测主要应用于滑坡、崩塌变形监测, 洞室 围岩变形监测, 地面沉降、采空区塌陷监测以及各类建筑工 程在施工、运营期间的监测和对环境的监测等 ${ }^{[1]}$ 。

\section{1 岩土体的变形监测}

岩土体的变形监测分为地面位移变形监测、洞壁位移变 形监测和岩土体内部位移变形监测几种。

\section{1 .1 地面位移变形监测}

主要采用的方法是: (1)用经纬仪、水准仪或光电测距仪 重复观测各测点的方向和水平、铅直距离的变化, 以此来判 定地面位移矢量随时间变化的情况, 测点可根据具体的条件 和要求布置成不同形式的观测线、网，一般在条件比较复杂
和位移较大的部位应适当加密; 2)对规模较大的地面变形还 可采用航空摄影或全球卫星定位系统来进行监测; 3采用伸 缩仪和倾斜计等简易方法进行监测; (4)采用钢尺或皮尺观测 测点的变化, 或用贴纸条的方法了解裂缝的张开情况。监测 结果应整理成位移随时间变化的关系曲线, 以此来分析位移 的变化和趋势 ${ }^{[2]}$ 。

\section{1 .2 洞壁位移变形监测}

洞壁岩体表面两点间的距离改变量的量测是通过收敛量 测来实现的，它被用于了解洞壁间的相对变形和边坡上张裂 缝的发展变化, 据此对工程稳定性趋势做出评价并对破坏的 时间做出预报。测量的方法可采用专门的收敛计进行简易的 可用钢卷尺直接量测。收敛计可分为垂直方向、水平方向及 倾斜方向等几种, 分别用工具测量垂直、水平及倾斜方向的 变形 ${ }^{[3]}$ 。

\section{1 .3 岩土体内部位移变形监测}

准确地测定岩土体内部位移变化, 目前常用的方法有管 式应变计、倾斜计和位移计等, 它们皆要借助于钻孔进行监测。 管式应变计是在聚氯乙烯管上隔一定距离贴上电阻应变片, 
随后将其埋植于钻孔中，用于测量由于岩土体内部位移而引 起的管子变形。倾斜计是一种量测钻孔弯曲的装置, 它是把 传感器固定在钻孔不同的位置上, 用以测量预定程度的变形, 从而了解不同深度岩土体的变形情况。位移计是一种靠测量 金属线伸长来确定岩土体变形的装置, 一般采用多层位移计 量测，将金属线固定于不同层位的岩土体上，末端固定于深 部不动体上, 用以测量不同深度岩土体随时间的位移变形。

\section{2 岩土体内部的应力监测}

岩土体内部的应力监测是借助于压力传感器装置来实现 的, 一般将压力传感器埋设在结构物与岩土体的接触面上或 预埋在岩土体中。目前, 国际采用的压力传感器多为压力盒, 有液压式、气压式、钢弦式和电阻应变式等不同形式和规格 的产品, 以后两种较为常用。由于压力观测是在施工和运营 期间进行的，互有干扰，所以务必防止量测装置被破坏。为 了保证量测数据的可靠性, 压力盒应有足够的强度和耐久性, 加压、减压线形良好, 能适应温度和环境变化而保持稳定。 埋设时应避免对岩土体的扰动, 回填土的性状应与周围土体 一致。通过定时监测, 便可获得岩土压力随时间的变化资料。

\section{3 不良地质作用和地质灾害的监测}

工程建设过程中, 由于受到各种内、外因素的影响, 如 滑坡、崩塌、泥石流、岩溶等, 这些不良地质作用及其所带 来的地质灾害都会直接影响到工程的安全乃至人民生命财产 的安全。因此, 在现阶段的工程建设中对上述不良地质作用 和地质灾害的监测已经是不可缺少的工作。

不良地质作用和地质灾害监测的目的: 一是正确判定、 评价已有不良地质作用和地质灾害的危害性, 监视其对环境、 建筑物和对人民财产的影响, 对灾害的发生进行预报; 二是 为防治灾害提供科学依据; 三是预测灾害发生及发展趋势和 检验整治后的效果, 为今后的防治、预测提供经验教训。

根据不同的不良地质作用和地质灾害的情况开展的地质 灾害监测内容应包括以下几个方面。

（1）应进行不良地质作用和地质灾害监测的情况是: (1)场地及其附近有不良地质作用或地质灾害, 并可能危及工 程的安全或正常使用时; (2)工程建设和运行, 可能加速不良 地质作用的发展或引发地质灾害时; (3工程建设和运行, 对 附近环境可能产生显著不良影响时。

( 2) 岩溶土洞发育区应着重监测的内容是: (1)地面变形;
(2)地下水位的动态变化; (3)场区及其附近的抽水情况; (4)地 下水位变化对土洞发育和塌陷发生的影响。

（3）滑坡监测应包括下列内容: (1)滑坡体的位移; (2) 滑面位置及错动; (3)滑坡裂缝的发生和发展; (4)滑坡体内外 地下水位、流向、泉水流量和滑带孔隙水压力; (5)支挡结构 及其他工程设施的位移、变形、裂缝的发生和发展。

（4）当需判定崩塌剥离体或危岩的稳定性时, 应对张 裂缝进行监测。对可能造成较大危害的崩塌, 应进行系统监测, 并根据监测结果对可能发生崩塌的时间、规模、塌落方向和 途径、影响范围等做出预报。

(5) 对现采空区, 应进行地表移动和建筑物变形的观 测, 并应符合: (1)观测线宜平行和垂直矿层走向布置, 其长 度应超过移动盆地的范围; (2)观测点的间距可根据开采深度 确定, 并大致相等; (3)观测周期应根据地表变形速度和开采 深度确定。

（6）因城市或工业区抽水而引起区域性地面沉降，应 进行区域性的地面沉降监测, 监测要求和方法应按有关标准 进行。

\section{2 地下水的监测}

当建筑场地内有地下水存在时, 地下水的水位变化及其 腐蚀性（侵蚀性）和渗流破坏等不良地质作用，对工程的稳 定性、施工及正常使用都能产生严重的不利影响，必须予以 重视。当地下水水位在建筑物基础底面以下压缩层范围内上 升时, 水浸湿和软化岩土, 从而使地基土的强度降低, 压缩 性增大。尤其是对结构不稳定的岩土, 这种现象更为严重, 能导致建筑物的严重变形与破坏。当地下水在压缩层范围内 下降时, 则增加地基土的自重应力, 引起基础的附加沉降。

在建筑工程施工中遇到地下水时, 会增加施工难度。如 需处理地下水, 或降低地下水位, 工期和造价必将受到影响。 如基坑开挖时遇含水层, 有可能会发生涌水涌沙事故, 延长 工期, 直接影响经济指标。因此, 在开挖基坑 (槽) 时, 应 预先做好排水工作。这样, 可以减少或避免地下水的影响。

周围环境的改变, 将会引起地下水位的变化, 从而可能 产生渗流破坏、基坑突涌、冻胀等不良地质作用, 其中以渗 流破坏最为常见。渗流破坏系指土（岩）体在地下水渗流的 作用下其颗粒发生移动，或颗粒成分及土的结构发生改变的 现象。渗流破坏的发生及形式不仅决定于渗透水流动水力的 
大小，同时与土的颗粒级配、密度及透水性等条件有关，而 对其影响最大的是地下水的动水压力 ${ }^{[4]}$ 。

对于地下水监测, 不同于水文地质学中的 “长期观测” 。 因观测是针对地下水的天然水位、水质和水量的时间变化规 律的观测，一般仅提供动态观测资料。而监测则不仅仅是观测， 还要根据观测资料提出问题, 制定处理方案和措施。

当地下水水位变化影响到建筑工程的稳定时, 需对地下 水进行监测。

\section{1 对地下水实施监测的情况}

对地下水实施监测的情况有: 地下水位升降影响岩土稳 定时; 地下水位上升产生浮托力, 对地下室或地下构筑物的 防潮、防水或稳定性产生较大影响时; 施工降水对拟建工程 或相邻工程有较大影响时; 施工或环境条件改变, 造成的孔 隙水压力、地下水压力变化, 对工程设计或施工有较大影响时; 地下水位的下降造成区域性地面下沉时; 地下水位的升降可 能使岩土产生软化、湿陷、胀缩时; 需要进行污染物运移对 环境影响的评价时。

\section{2 监测工作的布置}

应根据监测目的、场地条件、工程要求和水位地质条件 决定监测工作的布置。地下水监测方法应符合下列规定。

（1）地下水位的监测，可设置专门的地下水位观测孔， 或利用水井、泉等进行。

（2）孔隙水压力、地下水压力的监测, 可采用孔隙水 压力计、测压计进行。

(3) 用化学分析法监测水质时, 采样次数每年不应少 于 4 次, 并进行相关项目的分析。

(4) 动态监测时间不应少于一个水文年。
（5）当孔隙水压力变化影响工程安全时, 应在孔隙水 压力降至安全值后方可停止监测。

（6）受地下水浮托力的工程, 地下水压力监测应进行 至工程荷载大于浮托力后方可停止监测。

\section{3 地下水的监测布置及内容}

根据岩土体的性状和工程类型, 对于地下水压力 (水位) 和水质的监测，一般顺延地下水流向布置观测线。在水位 变化较大的地段、上层滞水或裂隙水变化聚集地带, 都应 布置观测孔。基坑开挖工程降水的监测孔应垂直基坑长边 布置观测线，其深度应达到基础施工的最大降水深度以下 $1 \mathrm{~m}$ 处。

地下水监测的内容包括: 地下水位的升降、变化幅度及 其与地表水、大气降水的关系, 工程降水对地质环境及建筑 物的影响深基础、地下洞室、斜坡、岸边工程施工对软土地 基孔隙水压力和地下水压力的观测监控, 管涌和流土现象对 动水压力的监测, 通过评价地下水对建筑工程侵蚀性和腐蚀 性而对地下水水质的监测等。

\section{参考文献}

[1] 关键超, 韦少典. 柳州市静兰大桥改建工程地质勘察及监测 [J]. 城 市勘测 , 2012(06): 163-167.

[2] 魏虎, 王开成, 冯鹏, 等. 测氡技术的工程地质应用及其在三峡 库区滑坡监测中的应用展望 [J]. 重庆交通大学学报 (自然科学 版),2003,22(s1):117-120.

[3] 杨林德, 潘洪科, 王志义. 复杂工程地质条件下公路隧道开挖及其 监控量测 [J]. 公路工程 ,2006,31(3):1-5.

[4] 张学礼, 徐乐昌. 地浸采铀地下水污染防治措施探讨 [J]. 中国人口 资源与环境,2015 (S2):360-364. 